\title{
CERITA TENTANG BIDADARI MANDI DAN FUNGSINYA SEBAGAI SARANA KONSERVASI SUMBER DAYA AIR
}

\author{
Yostiani Noor Asmi Harini ${ }^{1}$, Tedi Permadi ${ }^{2}$ \\ Departemen Pendidikan Bahasa dan Sastra Indonesia ${ }^{12}$ \\ FPBS, Universitas Pendidikan Indonesia \\ Author correspondence : yostiani@upi.edu
}

\begin{abstract}
Abstrak
Di Kabupaten Maros, Makassar, terdapat Kolam Jamala. Menurut cerita masyarakat, Kolam Jamala atau Telaga Bidadari merupakan tempat mandi bidadari. Bahkan, karena cerita tersebut, Kolam Jamala pun dipercaya memiliki khasiat dapat menyembuhkan berbagai penyakit bahkan menghindarkan orang yang mandi disana dari guna-guna. Di Jawa Barat, terdapat cerita tentang Jaka Tarub. Penggerak utama dalam cerita tersebut adalah turunnya para bidadari dari kahyangan yang kemudian mandi di sungai yang berada di bumi. Peristiwa tersebut menyebabkan Jaka Tarub terpesona oleh kecantikan sang bidadari sehingga dirinya mencuri salah satu selendang sang bidadari (Nawang Wulan). Kedua cerita tersebut memiliki kesamaan yaitu adanya peristiwa bidadari mandi dan latar tempat bidadari mandi (sungai/telaga). Pertanyaan yang kemudian muncul dalam benak kami adalah: mengapa dalam cerita rakyat nusantara tidak ada satu pun kisah yang di dalamnya terdapat tokoh dewa atau bidadara yang dikisahkan mandi di bumi? Setelah ditelusuri menggunakan pendekatan folklor, tampak bahwa cerita tentang bidadari mandi berfungsi sebagai sarana konservasi sumber daya air. Mengapa bidadari (perempuan)? Karena perempuan dipercaya masyarakat sebagai "ibu bumi".
\end{abstract}

Kata kunci: bidadari mandi, folklor, dan konservasi sumber daya air

\begin{abstract}
Kolam Jamala been in Maros, Makassar. According the story, Kolam Jamala or Telaga Bidadari is a place bathing nymphs. In fact, because of the story, people believed that Kolam Jamala have the power of healing various diseases and even prevent people who bathe there from witchcraft. In West Java, there is a story about Jaka Tarub. The main mover in the story is the fall of angels from heaven who then bathe in a earth river. Jaka Tarub be carried away by the beauty of nymphs so he stole one nymph shawl (Nawang Wulan). Both of these stories have a same patern: event and setting (river/lake). The question is: why in the folklore no one telling about male nymphs bathing? By studies of the folklore, that fungtion of the story is serve as a means of convervation of water resources. Why nymps (women)? Because women are trusted as "mother earth".
\end{abstract}

Keyword: bathing nymph, folklore, and conservation of water resources.

\section{Pendahuluan}

Di nusantara, banyak cerita rakyat yang mengisahkan tentang bidadari. Bidadari dalam KBBI (2008:196) adalah putri atau dewi dari kayangan dan merupakan perempuan yang sangat cantik. Irmawati (2013) menuliskan bahwa secara visual, bidadari adalah perempuan suci yang menyenangkan dan menyejukkan mata yang memandang, serta menenteramkan hati saat dipandang. Bidadari memiliki rupa jelita dan akhlak mulia. Menurut Syakban (seperti dikutip Irmawati, 2013), "dalam pemikiran Islam, bidadari adalah penghuni surga. Perempuan yang shalehah akan menjadi bidadari di surga. Sementara itu, laki-laki yang syahid dijanjikan mendapatkan bidadari surga. Hal tersebut menunjukkan bahwa bidadari adalah sesuatu yang diinginkan".

Cerita tentang bidadari memiliki banyak versi. Berdasarkan informasi yang diperoleh Atisah (2015), pada tahun 1965 pernah ada penelitian mengenai cerita bidadari yang dilakukan oleh Darusuprapto. Pada penelitian tersebut, Darusuprapto membandingkan cerita "Lumaluindung dan Mamanua" dengan "Jaka Tarub". Pada tahun 
1985, Djamaris meneliti cerita "Malim Deman" dan menghubungkannya dengan cerita lain. Mardiyanto, dkk. (1987) meneliti "Analisis Perbandingan Struktur Cerita Bidadari dalam Sastra Nusantara". Dalam penelitiannya tersebut, Mardiyanto membandingkan tujuh cerita bidadari, yaitu: (1) "Jaka Tarub", (2) "Arya Menak Kawin dengan Bidadari", (3) “Tiga Piatu", (4) “Telaga Bidadari”, (5) "Polo Padang”, (6) "Oheo", dan (7) "Manusia Pertama di Kepulauan Talaud". Perbandingan ketujuh cerita tersebut meliputi perbandingan tema, amanat, alur, latar, dan penokohan.

Badan Bahasa pada tahun 2003 telah mendokumentasikan dan meneliti 26 cerita bidadari dari berbagai etnis yang ada di nusantara. Cerita tersebut yaitu: (1) "Malem Dewa", Cerita Rakyat Daerah Aceh, Gayo, (2) "Putri Bensu", Cerita Rakyat Daerah Aceh, Gayo,(3) "Tupai Malimdewa", Cerita Rakyat Daerah Aceh Selatan, (4) "Si Boru Leang Nagurasta", cerita Rakyat Daerah Sumatra Utara, Batak Toba, (5) "Mambang Linau", Cerita Rakyat Daerah Riau, (6) "Sidang Belawan", Cerita Rakyat Daerah Lampung, (7) "Sumur Tujuh", Cerita Rakyat Daerah Jawa Barat, Banten, (8) "Jaka Tarub", Cerita Rakyat Daerah Jawa Tengah, (9) "Aryo Menak Kawin dengan Bidadari”, Cerita Rakyat Daerah Jawa Timur, Madura (10) "Tiga Piatu”, Cerita Rakyat Daerah Bali, (11) "Rajapala", Cerita Rakyat Daerah Bali, (12) "Silang Gading”, Cerita Rakyat Daerah Kalimantan Tengah, (13) "Telaga Bidadari”, Cerita Rakyat Daerah Kalimantan Selatan, (14) "Mamanua", Cerita Rakyat Daerah Sulawesi Utara, Minahasa, (15) "Mamanua dan Wulansendow", Cerita Rakyat Daerah Sulawesi Utara, Manado, (16) "Manusia Pertama di Kepulauan Talaud", Cerita Rakyat Daerah Sulawesi Utara, Sangir Talaud, (17) "Gumansalangi", Cerita Rakyat Daerah Sulawesi Utara, Sangir Talaud, (18) "TulaTulano Ratono Fitu Ghulu Bidhadari”, Cerita Rakyat Daerah Sulawesi Tenggara, (19) "Oheo", Cerita 20) "Putri Satarina", Cerita Rakyat Daerah Sulawesi Tenggara, Walio, (21) "Kacoq Parukiq", Cerita Rakyat Daerah Sulawesi Selatan, Mandar, (22) "Polo Padang”, Cerita Rakyat Daerah Sulawesi Selatan, Toraja, (23) "Orang yang Memperistri Putri dari Kayangan", Cerita Rakyat Daerah Sulawesi Tengah, (24) "Meraksamana dan Siraiman", Cerita Rakyat Daerah Irian Jaya, (25) "Putri Bungsu dari Danau", Cerita Rakyat Daerah Papua, "Wamena", (26) "Putri Kayangan", Cerita Rakyat Daerah Papua, Ekagi.

Pada tahun 2011, Ahmadi meneliti "Cerita Rakyat Pulau Raas dalam Konteks Psikoanalisis Carl G. Jung”. Dalam penelitiannya, terdapat pembahasan mengenai cerita "Kaleter". Kaleter ialah nama tokoh lelaki miskin yang kemudian menikah dengan bidadari karena dia mencuri pakaian bidadari yang tengah mandi di taman pemandian yang terdapat di hutan.

Pada tahun 2014, terdapat penelitian dengan motif cerita yang serupa dengan cerita "Kaleter". Ialah Rasyid meneliti kisah "Botu Liodu Lei Lahilote". Berbeda dengan Ahmadi yang meneliti berdasarkan konteks psikoanalisis, Rasyid meneliti struktur aktansial dan fungsional cerita rakyat yang berasal dari Gorontalo tersebut.

Pada tahun 2015, terdapat penelitian dengan motif manusia yang menikah dengan bidadari yaitu dalam cerita rakyat "Lalan Belek" (Rejang, Bengkulu). Atisah meneliti motif yang terdapat dalam cerita bidadari tersebut berdasarkan motif index yang dikemukakan Stith Thompson (1966). Cerita tersebut diteliti oleh Atisah dan dimuat di jurnal Metasastra Vol 8 No. 2 (Desember 2015). Dalam penelitiannya, Atisah mengungkapkan bahwa pernikahan laki-laki bumi (dunia bawah) dengan bidadari (putri dari kayangan, dunia atas) merupakan perkawinan dua dunia yang berbeda. Komitmen sebelum pernikahan yang telah disepakati bersama ternyata dilanggar sang suami sehingga bangunan rumah tangga itu akhirnya hancur. Menurut Atisah, dalam pernikahan 
yang ideal, untuk mempertahankan keutuhan rumah tangga sang suami dan istri harus bekerja sama dan saling mengisi

Cerita rakyat yang telah saya paparkan di atas termasuk ke dalam cerita bidadari yang memiliki beberapa motif yaitu: 1) bidadari turun mandi; 2) pencurian baju bidadari; 3) manusia menikah dengan bidadari; 4) benda ajaib yang diterima dari bidadari/istri; 5) dilanggarnya janji sang suami kepada istri/bidadari; dan lain-lain.

Berdasarkan penelusuran terhadap penelitian terdahulu, belum ada penelitian yang mengaitkan cerita bidadari terutama motif bidadari mandi sebagai sarana konservasi sumber daya air. Hal ini menjadi penting untuk dilakukan mengingat sastra sangat berperan penting sebagai sarana menjaga kelestarian lingkungan.

Cerita rakyat yang dijadikan objek penelitian adalah cerita rakyat "Kolam Jamala" atau "Telaga Bidadari" yang berasal dari Kabupaten Maros, Sulawesi Selatan. Data diambil pada tanggal 26 April 2016. Pada penelitian ini, dideskripsikan relasi antara bidadari mandi dan air, serta peran hal tersebut dalam konservasi sumber daya air.

\section{Pembahasan}

Kolam Jamala atau Telaga Bidadari berada di Kabupaten Maros, Sulawesi Selatan. Kolam ini berada di kawasan wisata Bantimurung. Di Bantimurung terdapat air terjun dan dikenal sebagai "The Kingdom of Butterfly" karena keanekaragaman kupu-kupunya. Di sana dikembangkan pula tempat penangkaran kupu-kupu yang dapat difungsikan sebagai wahana pendidikan dan konservasi kupu-kupu. Sebelum menuju air terjun, pengunjung dapat melihat keberadaan Kolam Jamala.

Menurut informan, konon kolam ini merupakan tempat mandi bidadari. Oleh sebab itu, kolam ini disebut juga sebagai Telaga Bidadari. Informan pun menceritakan bahwa air yang terdapat di kolam tersebut dipercaya berkhasiat menyembuhkan berbagai penyakit bahkan dapat menghindarkan seseorang dari pengaruh guna-guna atau sihir. Selain itu, kolam ini pun dipercaya dapat membuat seseorang yang mandi di tempat tersebut akan segera mendapatkan jodoh.

Keberadaan motif bidadari mandi di berbagai daerah di Indonesia dan di berbagai belahan dunia menurut Jung seperti dikutip Danandjaja (2002) bukan disebabkan penyebaran melainkan disebabkan penemuan-penemuan yang berdiri sendiri. Cerita tersebut memiliki kemiripan karena adanya kesadaran bersama yang terpendam (collective unconscious) pada setiap umat manusia yang diwarisinya secara biologis. Menurutnya, semua manusia memiliki collective unconscious yang berupa mimpi-mimpi bertema universal yang terjadi karena manusia memiliki proyeksi keinginan individu sebagai anggota umat manusia.

Jung seperti dikutip Ahmadi (2011) menggunakan istilah arketipe untuk menamai ide yang mempribadi yang secara psikologis terepresentasi melalui mimpi dan cerita rakyat yang tercipta karena adanya ketidaksadaran kolektif. Dalam arketipe, terdapat konsep figur arketipal, situasi arketipal, objek arketipal, dan imaji arketipal.

Figur arketipal adalah representasi tokoh dalam cerita rakyat. Tokoh dapat berupa pahlawan, ayah, anak, ibu, dan tokoh lainnya. Situasi arketipal adalah hal yang berkaitan dengan peristiwa yang terdapat dalam cerita rakyat. Situasi arketipal dapat tampak melalui kelahiran, perpisahan, kematian, pernikahan, dan lain-lain. Objek arketipal adalah hal yang tampak melalui matahari, air, ikan, dan objek lainnya. Kemudian, imaji arketipal adalah perlambang dalam cerita rakyat yang samar, tidak diketahui atau tersembunyi karena sifatnya multitafsir. Imaji dalam kaitannya dengan arketipal, sebagaimana 
diungkapkan Jung dapat dimaknai pula berdasarkan pada relativitas ruang dan waktu dapat muncul di tempat yang lain.

Dalam cerita Kolam Jamala, terdapat figur arketipal yaitu bidadari. Bidadari menjadi figur arketipal karena diberbagai belahan dunia memiliki imajinasi yang relatif sama tentang bidadari. Bidadari yang dikisahkan dalam cerita Kolam Jamala ialah sosok perempuan yang berasal dari kayangan yang memiliki fisik sangat cantik jelita.

Situasi arketipal dalam cerita adalah peristiwa mandi yang dilakukan tokoh bidadari. Hal yang kemudian menjadi pertanyaan adalah: mengapa dalam cerita rakyat nusantara banyak sekali motif bidadari kayangan turun ke bumi untuk sekadar "menumpang mandi"? Apakah di kayangan tidak terdapat kolam atau telaga yang dapat digunakan para bidadari untuk mandi? Dan, mengapa tidak ada dewa yang berasal dari kayangan dikisahkan "menumpang mandi" di bumi?

Bidadari dari kayangan turun ke bumi untuk sekadar "menumpang mandi" dapat dimaknai sebagai keberadaan sesuatu yang indah yang terdapat di dalam kolam/telaga yang tidak dimiliki kayangan. Bumi dikisahkan sebagai tempat yang indah bahkan keindahannya mengakibatkan bidadari ingin mandi di sumber air/tempat yang dialiri air yang terdapat di bumi. Dalam cerita belum ditemukan adanya peristiwa mandi yang dilakukan dewa. Hal tersebut dapat dimaknai bahwa "keindahan" dilekatkan pada perempuan (bidadari) bukan pada laki-laki (dewa). Hal ini dapat terjadi karena adanya mainstream yang terdapat dalam masyarakat. Tokoh dewa (laki-laki) dilekatkan dengan image yang maskulin sementara mandi merupakan image yang feminin. Hal tersebut tampak dalam adanya peristiwa bidadari menanggalkan pakaiannya yang dalam beberapa kisah bermotif bidadari mengakibatkan sang bidadari tidak dapat kembali ke kayangan karena pakaiannya dicuri lelaki. Perempuan dalam satu sisi dikisahkan memiliki keagungan tersendiri ketika dia mengenakan pakaian (bidadari). Akan tetapi, keagungan tersebut dapat dimaknai sebagai hal yang ambivalen karena di sisi lain, hal itulah yang mengakibatkan ia tidak dapat kembali ke kayangan: karena membuat lelaki terpesona kemudian mengakibatkan lelaki tersebut mencuri pakaian bidadari. Selain itu, kita dapat melihat upacara adat yang melibatkan prosesi mandi.

Dalam masyarakat Jawa Tengah, terdapat ritual siraman (mandi) yang dilakukan sehari sebelum pengantin melaksanakan ijab qabul. Dalam siraman, memang kedua mempelai melakukan prosesi siraman. Akan tetapi, prosesi siraman ini kemudian dapat berlanjut bagi perempuan saat perempuan hamil. Saat perempuan hamil tujuh bulan, ada ritual siraman. Berbeda dengan laki-laki yang istrinya hamil tujuh bulan, sang suami tidak perlu menjalani prosesi siraman.

Menurut Irmawati (2013), upacara siraman dilakukan perempuan karena konon para bidadari akan turun bersama bersuka ria. Calon pengantin perempuan melakukan siraman agar dirinya secantik bidadari. Berdasarkan hal tersebut, tampak bahwa perempuan dan prosesi penyucian diri sangat berkaitan erat. Hal tersebut dapat dikaitkan pula dengan karakteristik air yang merupakan objek arketipal.

Air sebagai objek arketipal memiliki karakteristik menyucikan. Dalam berbagai tradisi, air digunakan sebagai sarana penyucian diri. Dalam Islam, umat Islam diharuskan melakukan wudhu ketika akan salat. Bahkan, dalam Islam dikenal istilah mandi besar untuk menyucikan diri. Air sebagai objek arketipal dapat dipandang pula sebagai sesuatu yang memiliki dualisme. Di satu sisi, ia dapat sangat bermanfaat dalam kehidupan namun di sisi lain ia dapat sangat merugikan umat manusia. Air dapat sangat bermanfaat bahkan dalam cerita rakyat Kolam Jamala dikisahkan sebagai imaji arketipal berupa tuah menghindarkan seseorang dari guna-guna. Meskipun demikian, air dapat pula menjelma 
tuba yang membawa kehancuran bagi manusia yang tidak dapat menjaganya misalnya bencana banjir.

Berdasarkan penelusuran di atas, tampak bahwa cerita tentang bidadari mandi berfungsi sebagai sarana konservasi sumber daya air. Koservasi sumber daya air menurut Undang-Undang RI No. 7 Tahun 2004 tentang Sumber Daya Air, adalah upaya memelihara keberadaan serta keberlanjutan keadaan, sifat, dan fungsi sumber daya air agar senantiasa tersedia dalam kuantitas dan kualitas yang memadai untuk memenuhi kebutuhan makhluk hidup, baik pada waktu sekarang maupun yang akan datang. Hal tersebut dapat terlihat dengan mengaitkan konteks kisah tersebut. Cerita tentang bidadari mandi, terutama cerita rakyat mengenai Kolam Jamala yang terdapat di Kabupaten Maros, Makassar, Sulawesi Selatan, merupakan kisah yang sengaja dibuat leluhur kita agar kita menjaga kelestarian lingkungan hidup terutama kelestarian air. Hal tersebut dapat dikaitkan pula dengan keberadaan mitos mengenai tuah yang terdapat dalam Kolam Jamala. Dengan adanya mitos tersebut, masyarakat diajak untuk berhati-hati dan tetap menjaga kelestarian air agar dapat memanfaatkan air dengan sebaik-baiknya. Hal tersebut senada dengan apa yang diungkapkan Nuraini (2015) mitos, larangan atau tabu dapat dimanfaatkan untuk menjaga kelestarian lingkungan.

Relasi antara bidadari, mandi, air, dan tuah yang terdapat di dalam sumber air tersebut memiliki fungsi dalam kehidupan bersama masyarakat Kabupaten Maros yaitu sebagai sarana konservasi sumber daya air. Mengapa bidadari (perempuan)? Karena perempuan dipercaya masyarakat sebagai "ibu bumi". Hal tersebut tampak pula dalam cerita rakyat lain. Misalnya saja dalam cerita masyarakat India. Di India, terdapat Sungai Gangga. Nama tersebut diambil dari nama Dewi Gangga. Dewi Gangga ialah dewi kesuburan dan kemakmuran yang mampu menyucikan semua dosa-dosa makhluk hidup.

Menurut Taum (2013) Bangsa Indonesia menyebut tanah air sebagai "ibu pertiwi." Dalam imaginasi bangsa Indonesia, laut pun merupakan "ibu" dengan segala kelembutan, kasih sayang, dan pemberi kehidupan. Di Indonesia (seperti di Mesir) bahureksa laut mendapat bentuk sosok perempuan. Seperti halnya bumi, tanah dan air, laut merupakan unsur pengandung - pelahir - dan penyusui kehidupan (Setiawan seperti dikutip Taum: 2013). Masyarakat Pulau Buru selain mengenal Ina Kabuki, ratu yang bertahta di dasar Teluk Kayeli, juga mempunyai tokoh Boki Ronja(ng), "pamali" atau bahureksa sungai Wai Apu. Bentuk feminin ini barangkali juga karena, di hadapan langit, laut terletak di bawah. Masyarakat nelayan Lamalera menyebut laut sebagai Ina Fae Belé (Lamaholot: Ina Fae (dari kata: Kefae atau Kfae. Lamaholot: Kewae/Kwae: Istri) Belé artinya: Ibunda yang maharahim. Masyarakat Lamalera selama berabad-abad hidup dari hasil laut, terutama berburu ikan paus. Laut memiliki peran amat sentral dalam kehidupan orang Lamalera. Laut dengan demikian memiliki beberapa julukan atau sapaan. Dalam Sastra laut Lamalera, selain Ina Fae Belé, Laut juga disebut sebagai: Sedo Basa Hari Lolo: Ibunda yang maharahim, mahapengasih, bunda yang senantiasa mengandung, melahirkan, membesarkan memelihara anak-anaknya dengan menyediakan semua yang anak-anaknya butuhkan. Dalam nyanyian-nyanyian memanggil angin dan ungkapan-ungkapan adat ketika menangkap ikan paus, pari, hiu, dll, laut disebut dengan berbagai nama, Ina Lefa (Bunda Lautan), Ina Soro Budi: Ibu yang memberi hatinya kepada anak-anaknya (Nestorman: 2013 seperti dikutip Taum: 2013).

Menurut Taum (2013), terdapat dua alasan mengapa laut dapat dimaknai sebagai simbol perempuan. Pertama, dalam konsep masyarakat di luar Pulau Jawa, perempuan dipahami sebagai pemberi dan pelindung kehidupan. Perempuan lebih dimaknai sebagai manusia yang lembut dan penuh kasih. Itulah sebabnya banyak sekali suku-suku bangsa 
di luar Jawa yang menjadi pelaut ulung (dengan kapal Phinisi) dan bahkan ada suku laut yang dikenal sebagai gypsi laut seperti suku Bajao di Sulawesi Selatan. Laut juga dipahami sebagai ibu yang member kehidupan, seperti terlihat jelas dalam legenda Bau Nyale masyarakat suku Sasak. Kedua, dalam konsep Jawa, perempuan dipahami sebagai çakti yang dilukiskan sebagai maha hebat dan selalu dilukiskan sebagai sesuatu yang "mengerikan".

\section{Simpulan}

Hasil penelitian menunjukkan bahwa tokoh bidadari dapat dilihat sebagai tokoh arketipal. Aktivitas mandi dapat dimaknai sebagai situasi arketipal. Sementara itu, air dapat dimaknai sebagai objek arketipal. Imaji arketipal dalam cerita ini ialah peristiwa mandi bidadari yang kemudian dipercaya masyarakat berdampak pada tuah yang berada dalam kolam yaitu semacam khasiat menghindarkan seseorang dari guna-guna atau pengaruh sihir. Cerita bidadari dengan motif bidadari turun mandi pada cerita rakyat Kolam Jamala di Kab. Maros, Makassar, Sulawesi Selatan ini berfungsi sebagai sarana konservasi sumber daya air.

\section{Daftar Pustaka}

Ahmadi, Anas. 2011. "Cerita Rakyat Pulau Raas dalam Konteks Psikoanalsis Carl G. Jung.” Jurnal MDA. Tahun 2011, Vol. 24, No. 2. Hal. 109-116. [Daring] Tersedia di: $\quad$ http://journal.unair.ac.id/filerPDF/03\%20anas\%20ahmadiCERITA\%20RAKYAT\%20PULAU\%20RAAS\%20edit\%20MDA.pdf (Diakses pada 16 Juli 2016)

Atisah. 2015. "Lalan Belek" Cerita Bidadari dari Rejang Bengkulu: Kajian Motif. Jurnal Metasastra, Vol. 8 No. 2, Desember 2015: 239-248.

Danandjaja, James. 2002. Folklor Indonesia: Ilmu Gosip, Dongeng, dan lain-lain. Jakarta: Pustaka Utama Grafiti.

Irmawati, Waryunah. 2013. "Makna Simbolik Upacara Siraman Pengantin Adat Jawa". Jurnal Walisongo Vol 21, No. 2. [Daring] Tersedia di http://journal.walisongo.ac.id/index.php/walisongo/article/view/247/228 (Diakses pada 16 Juli 2016)

Nuraini, Cut. 2015. "Kearifan Lingkungan dalam Pengelolaan Hutan, Tanah, dan Sungai di Desa Singengu, Kecamatan Kotanopan Kabupaten Mandailing Natal, Sumatera Utara”. Jurnal Manusia \& Lingkungan, Vol. 22 No. 1, Maret 2015. [Daring] Tersedia di: http://jpe-ces.ugm.ac.id/ojs/index.php/JML/article/view/446 (Diakses pada 16 Juli 2016)

Rasyid, Armiati. 2014. "Struktur Aktansial dan Fungsional Cerita Rakyat Gorontalo: Asal Mula Botu Lidou Lei Lahilote". Jurnal Telaga Bahasa. Daring. Tersedia di: http://telagabahasa.org/jurnal/index.php/telagabahasa/article/view/11 (Diakses pada 16 Juli 2016) 
Taum, Yoseph Yapi. 2013. "Berbagai Mitos tentang Laut: Mengungkap Konsep Bahari Bangsa Indonesia." Makalah dalam Kongres Internasional Folklore Asia III di Hotel Inna Garuda, Yogyakarta, 7-9 Juni 2013.

Thompson, Stith. 1966. Motif-Index of Folk Literature. Revised and Enlanrged Edition 6 Vol. Bloomington \& London: Indoana University Press.

Tim Penyusun Kamus. 2008. Kamus Besar Bahasa Indonesia. Jakarta: Pusat Bahasa.

Tim Penyusun. 2004. Undang-Undang RI No. 7 Tahun 2004 tentang Sumber Daya Air. Yogyakarta: Pustaka Widyatama. 